\title{
As páginas web de agrupamentos de escolas e os pais: comunicação e participação?
}

\section{Web sites of grouping of schools and the parents: communication and participation?}

\author{
Fernanda Martins \\ Universidade do Minho
}

\begin{abstract}
Resumo
Com a introdução das novas tecnologias de informação os canais de comunicação entre a escola e a família têm sofrido alterações, surgindo os canais de comunicação tecnológicos. Face a esta nova realidade, e no âmbito de um trabalho mais amplo, procedemos a uma análise preliminar e exploratória de um destes canais: as páginas web de agrupamentos de escolas. Assim, procuramos saber: i) de um determinado conjunto de agrupamentos quantos possuem páginas web; ii) que espaços (in)existentes nas páginas web para feedback por parte dos pais e iii) se há nestas páginas web divulgação de estruturas de participação coletiva e direta, designadamente das associações de pais.

Palabras chave: páginas web, agrupamentos, pais, comunicação e participação
\end{abstract}

\begin{abstract}
With the introduction of the new technologies of information, the communication channels between the school and the family have been undergoing changes, with the emergence of the channels of technological communication. In the light of this new reality, and within a broader work of investigation, we have proceeded to a preliminary and exploratory analysis of one of these channels: the web pages of groupings of schools. Thus, we seek to know: i) of a set of groupings of schools, how many of them have web pages; ii) how much in(existent) room for parents' feedback, and, is there, in these web pages, revelation of groupal structures and of direct participation, namely of parents' associations.
\end{abstract}

Key-words: web pages, groupings of schools, parents, communication and participation

\section{Introdução}

Nesta longa e complexa marcha do clip a clic (cf. Fernandez Enguita e Vázques Cupeiro, 2017) assisti-se à introdução na educação das novas tecnologias de informação que, por sua vez, veio alterar os canais tradicionais de comunicação entre a escola e a família, coexistindo na atualidade dois tipos de canais de comunicação, os tradicionais e os tecnológicos. Não obstante esta nova realidade, são escassos trabalhos que tomem por objeto de estudo estas novas formas de comunicação e as alterações que introduzem na relação entre escola e família. Neste sentido, no âmbito de um trabalho mais amplo, inscrito nos domínios da organização escolar e da sociologia da educação, pretendemos dar um contributo para o conhecimento desta nova realidade. De modo específico, pretendemos questionar se estas novas formas de comunicação consistem num contributo para potenciar a participação de pais e encarregados de educação na escola dos seus filhos ou se tais formas de comunicação induzem uma conceção de pai enquanto consumidor e recetáculo da informação, sem qualquer papel mais significativo na escola. Numa abordagem preliminar e exploratória, procedemos a uma análise de um dos canais de comunicação tecnológicos grupais: as páginas web de agrupamento de escolas na realidade portuguesa. Nesse sentido, e de modo mais concreto, na análise que desenvolvemos às páginas web procuramos saber: i) de um determinado conjunto de agrupamentos quantos possuem páginas web; ii) que espaços (in)existentes para feedback por parte dos pais e, finalmente, iii) se há nestas páginas web divulgação de estrutura de participação coletiva e direta, designadamente das associações de país.

\section{Comunicação escola-família}

A comunicação entre escola e família tem sido uma das vertentes estudadas no domínio da relação escola-família. Epstein, Coates, Salinas, Sanders \& Simon (1997:8) consideraram a comunicação escola-família como uma das modalidades de envolvimento dos pais na educação escolar dos seus filhos, incluindo neste domínio a comunicação sobre programas escolares, atividades da escola e progressos dos alunos. Nas palavras dos autores: "design effective forms of school-to-home and home-to-school 
communication about school programs and their children's progress".

Mais recentemente, Garreta Bochaca \& Macìa Bordala (2017:72) esclarecem que quando se referem a este conceito, comunicação entre família e escola, englobam dois tipos de atividades ou de interações comunicativas. Nas suas palavras:

"En primero lugar, la transmissión de información entre un emissor (generalmente maestro) y un receptor (generalmente progenitor), que és quien descodifica, interpreta y adquiere el mensaje, $Y$ en segundo lugar, la repetición de este también por parte del receptor, de manera que ambos agentes comparten y adquieren mensajes, créandose un continuum informativo de ida y vuelta. És decir, comunicación unidirecional, cujo objetivo es dar a conocer y compartir una información que uno posee, y comunicación bidirecional, que se construye sobre una estrutura de reciprocidade y que, por tanto, facilita o enriquecimento informacional de ambas partes".

Neste âmbito, de uma comunicação bidirecional, concebemos a comunicação como um importante meio para potenciar a participação (sobre este conceito $\mathrm{cf}$. Lima, 1992) dos pais na educação dos filhos, na medida em que através dos canais comunicativos é possível expor visões, discutir e negociar decisões sobre o funcionamento da escola em geral, afastando-se de uma conceção de pai enquanto consumidor e recetáculo da informação.

Não obstante esta potencialidade, dificuldades e obstáculos de diferente natureza existem neste domínio (cf. Garreta Bochaca \& Macìa Bordalba, 2017) e podem, inclusivamente, comprometer essa comunicação bidirecional, acabando um dos intervenientes por dominar a comunicação. Na realidade atual, apesar do surgimento de novos canais de comunicação, estas barreiras não desapareceram, tal como refere Beneyto-Seoane \& Cllet-Sabé (2016: 3), na esteira de outros autores:

"ante el uso de la tecnologia en el âmbito escolar, no solo se reproducen alguns factores de riesgo (socioeconómicos), sino que además se está generando nuevas barreras en la relación entre famílias y escuela como el acceso a las infraestructuras y a la información y el invisible engagement".

\section{Canais de comunicação na relação escola-família: o caso das páginas web}

Como aludimos no ponto anterior, atualmente a escola conta com novos canais de comunicação com os pais, sendo de distinguir entre canais de comunicação tradicionais e canais de comunicação tecnológicos. $\mathrm{Na}$ linha de trabalho de Garreta Bochaca \& Macìa Bordalba (2017:79-80), por canais tradicionais se entende "aquellos que han utilizado de forma habitual en los centros escolares y que no tien relación com las nuevas tecnologias (canales analógicos)", enquanto que canais tecnológicos se referem "a todas aquellas vías de comunicación que utilizan las herramientas digitales como medios para transmitir el mensaje".

Ainda ano seio destes dois tipos de comunicação, os autores distinguem entre canais de comunicação familiares (individuais) e canais grupais. Incluem nos canais tradicionais individuais os contactos pessoais, a agenda escola, as tutorias e nos grupais as circulares e notas, as reuniões gerais, os painéis de anúncios e as revistas da escola. No que se refere aos canais tecnológicos, no domínio individual incluem correio eletrónico, telefone e plataformas e nos grupais também as plataformas e correio eletrónico e, ainda, as páginas webs e blogs.

Desta diversidade de canais tecnológicos destacamos os grupais e dentro destes as páginas web, domínio sobre o qual recai a nossa investigação. Neste âmbito, gostaríamos de salientar que os autores identificam três funções das páginas web, a saber: descritiva, informativa e ilustrativa (Garrta Bochaca e Macìa Bordala, 2017:95). Na função descritiva incluem informação de carácter geral (quem somos, o que fazemos, o que nos define e como trabalhamos); no segundo tipo de função, na informativa, incluem informações de larga duração temporal, como calendário escolar, horários, ementas da cantina, bem como mensagens pontuais que se eliminam pouco tempo depois da sua realização; quanto à função ilustrativa, esta diz respeito a relatos a posteriori, materiais que mostram as atividades realizadas, sendo em muitos casos o código visual o mais utilizado.

Contudo, esta nova realidade merece um olhar crítico e atento quanto ao seu alcance para tornar a relação escola-família mais democrática. Nesse sentido, elencamos algumas críticas diretamente relacionadas com as páginas web, desde logo no que se refere ao seu acesso, segundo Beneyto-Seoane \& Collet-Sabé (2016), há famílias que mostram dificuldades no acesso às aplicações. Acresce outra crítica, o facto de as páginas web consistirem num canal de comunicação predominantemente unilateral, da escola para a família (Garreta Bochaca \& Macìa Bordalba, 2017; Beneyto-Seoane \& Collet-Sabé, 2016). Assim sendo, um carácter mais participativo por parte das famílias através das páginas web encontra-se praticamente ausente. Esta situação faz-nos apresentar, num registo apenas ilustrativo, duas questões: que espaços existem, nas referidas páginas, para os pais poderem dar um feedback relativamente ao que acontece na escola? Nas páginas webs encontram-se divulgados espaços de participação coletiva e direta dos pais (cf. Beneyto-Seoane \& Collet-Sabé, 2016)), como é o caso das associações de pais e encarregados de educação?

Tendo em conta este cenário complexo quanto os canais de comunicação tecnológicos na relação escola-família e a escassez de trabalhos que tomem por objeto de estudo estas novas formas de comunicação, realizamos uma análise, num registo preliminar e exploratório, a páginas web de agrupamentos de escolas, enquanto instrumento de comunicação entre escola e pais. 


\section{Notas metodológicas}

Para efeitos do presente trabalho selecionámos de forma aleatória, a partir de uma lista de agrupamentos de escolas existentes em Portugal, dez agrupamentos de escolas (apenas aqueles que incluem desde jardim de infância até ao $3^{\circ}$ Ciclo do Ensino Básico). O primeiro critério utilizado foi o de selecionar dois agrupamentos de cada uma das regiões do país (Norte, Centro, Lisboa, Alentejo e Algarve) e, como segundo critério, selecionar os dois primeiros agrupamentos de cada região que surgiam na respetiva lista, desde que pertencentes aos níveis de ensino acima enumerados, caso contrário avançamos para o agrupamento seguinte.

Procedemos à consulta das páginas web dos referidos agrupamentos durante um mês, durante o primeiro semestre de 2017. Neste domínio, importa esclarecer que as páginas web dos agrupamentos de escolas possuem um espaço público/livre e um espaço reservado (restrito a utilizadores), a nossa investigação nesta fase incide apenas sobre o espaço público das páginas web. Obedecendo aos critérios de anonimato não identificamos nenhum dos agrupamentos.

Fruto do trabalho analítico desta nova forma de comunicação na relação escola-família, procuramos conhecer quantos agrupamentos deste conjunto de dez agrupamentos possuem páginas web, que espaços (in)existentes no espaço público das páginas web para feedback por parte dos pais e, finalmente, se há no espaço público destas páginas web divulgação de estruturas de participação coletiva e direta, designadamente das associações de pais.

Será de salientar que os resultados agora apresentados assumem um carácter provisório na nossa investigação mais ampla, sendo necessário que estes dados sejam no futuro cotejados com os resultados obtidos da análise das páginas web dos demais agrupamentos. E, ainda, será de frisar que os resultados obtidos nesta fase se referem exclusivamente a este grupo, não existindo da nossa parte qualquer intenção da sua generalização. Não obstante estas limitações, o trabalho desenvolvido para este artigo revelou-se de crucial importância na medida em que possibilitou a construção de algumas categorias de análise das páginas web dos agrupamentos de escolas na realidade portuguesa, enquanto canal de comunicação na relação escola-família.

\section{Webs e pais: reduzidas possibilidades de comunicação e participação}

Da análise dos dez agrupamentos de escolas seleccionados (a partir da lista de agrupamentos existentes em Portugal e segundo os critérios anteriormente anunciados) verificamos que todos possuem páginas web. Este dado remete-nos para uma adesão significativa a esta nova ferramenta mobilizada pelos agrupamentos de escolas na rede pública. Podemos avançar, na esteira de Beneyto-Seoane \& Collet-Sabé (2016:5), com algumas hipóteses que fundamentem esta opção pelos respetivos agrupamentos. Os autores em causa, a partir de uma investigação que realizaram, identificaram diferentes propósitos nesta adesão, passamos a mencionar alguns destes. Desde logo uma certa necessidade por parte das escolas em não quererem ficar para trás, de encontrarem-se em dia com as inovações tecnológicas. Por outro lado, as páginas web podem também constituir um instrumento importante na busca de novos clientes. A este propósito numa das páginas por nós consultadas tivemos a possibilidade de observar que a mesma integra no seu espaço público um item designado rankings, com acesso direto às listas ordenadas de escolas publicadas pela imprensa na realidade portuguesa. Tal situação leva-nos a equacionar a existência da página com este intuito de cativar clientes e de promoção da imagem da escola (cf, Martins, 2009; Sousa, 2013) junto de potenciais clientes. Finalmente, na pesquisa dos autores mencionados, estes também encontraram como um dos propósitos melhorar a comunicação com todas as famílias. A partir daqui apraz-nos dizer que merece investigação futura para o caso dos agrupamentos de escolas da realidade portuguesa conhecer junto dos responsáveis dos agrupamentos os propósitos nesta opção pelas páginas web, neste momento avançamos apenas com o dado de que deste universo de dez agrupamentos de escolas a adesão é total a que o agrupamento tenha uma página web.

No que se refere à segunda dimensão que nos propusemos analisar: as páginas web como meio para potenciar a participação (feedback) dos pais, verificamos que na maioria dos casos as respetivas páginas não oferecem esta possibilidade. Não localizamos no espaço público das páginas web de grande parte dos dez agrupamentos qualquer item relacionado com solicitação de feedback por parte dos pais quanto ao funcionamento do agrupamento. Por exemplo, não encontramos espaços para os país deixarem na página web sugestões, opiniões e/ou reclamações. Estes resultados levam-nos a ponderar que os agrupamentos apresentam alguma insensibilidade/resistência a juízos que possam ser emitidos pelos pais e encarregados de educação. Desta forma, na maioria dos casos (em nove) se espera que os pais consultem a páginas e respetivas informações fornecidas pelo agrupamento e que as incorporem de forma passiva. Não obstante este cenário, apenas no espaço público de uma das páginas web pudemos identificar espaços para os pais comunicarem com a escola num sentido participativo. Trata-se da possibilidade de os pais terem voz através da página $w e b$. Num registo mais descritivo, mencionamos que no espaço público da página web em causa, logo na entrada/home, surge um item designado Outros, sendo um dos seus itens - imediatemente visível e não dependende da sua entrada neste ítem -, uma Caixa de sugestões do Agrupamento. No quadro abaixo, reproduzimos esta imagen para uma melhor visualizaçao desta possibilidade de participação: 
Quadro 1:

Visualização da Caixa de Sugestões

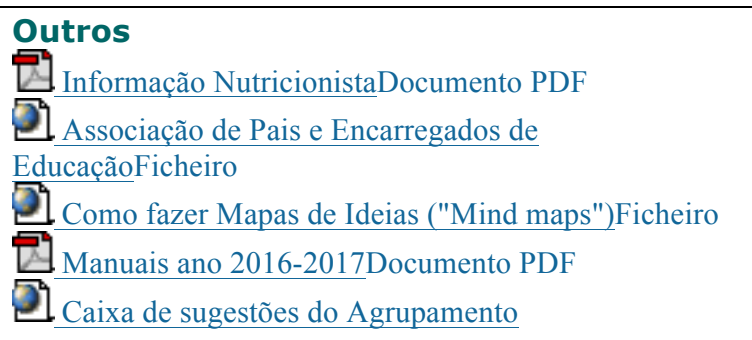

Ao clicar neste item aparece a explicitação, pela secção de avaliação interna e direção do agrupamento, da função desta caixa de sugestões que passamos a transcrever: "audição constante dos seus alunos e respetivos encarregados de educação, bem como de seus colaboradores, quer sejam pessoal docente ou não". Desta explicitação, fica claro que esta caixa poderá ser utilizada por diferentes atores educativos, sendo de destacar que surge em primeiro lugar os alunos e os respetivo encarregados de educação. Outro aspeto interessante nesta explicitação consiste na garantia de resposta por parte do agrupamento, tal como podemos ler: "se se identificar com o seu endereço de mail, dar-lhe-emos com maior brevidade possível uma resposta às suas sugestões, e lhe exporemos o processo de implementação da sua proposta ou dos constrangimentos em a implementar".

No que se refere à terceira dimensão em análise, a divulgação no espaço público das páginas web de uma das estruturas de participação coletiva e direta dos pais, a associação de pais e encarregados de educação, registamos um cenário plural e polifacetado. Do conjunto das dez páginas consultados, apenas em metade são mencionadas as associações de pais e encarregados de educação do agrupamento, nas demais cinco não há qualquer referência às mesmas. Consideramos, assim, que cinco agrupamentos estão a contribuir para divulgar e potenciar a participação coletiva e direta dos pais. No entanto, uma análise mais detalhada a estas cinco páginas, permite captar intensidades desiguais nesse processo. Neste sentido, verificamos que três dos cinco agrupamentos divulgam a associação de pais logo na abertura da página (no espaço que genericamente designa-se de home/entrada), sendo que nuns casos surge no topo da página e noutros dois na lateral esquerda, enquanto que em dois outros agrupamentos a associação é divulgada no interior de outro item, ou seja, apenas torna-se visível depois de entrar no referido item. Num destes agrupamentos surge na entrada o item Escola e dentro deste a associação, enquanto que no outro surge o item Encarregados de Educação e no seu interior a associação.

Uma vez no item associação, para o caso dos cinco agrupamentos mencionados, analisamos o seu conteúdo. Desta análise, constatamos que apenas em duas situações o item associação de pais apresenta conteúdo mais significativo para as famílias. Num caso, encontramos no interior desse item acesso direto ao site/página da respetiva associação, sendo essa página bastante completa, com informação diversa sobre a associação, no segundo caso encontramos os contatos da associação, acesso direto ao seu facebook e um pequeno texto de explicação sobre a respetiva associação e, ainda, um slogan, no fim da página, apelativo à participação (não o divulgamos para manter o anonimato). Nos demais casos, nos restantes três, num caso o acesso é reservado e não há absolutamente nenhuma informação sobre a associação, nem contatos da mesma; noutro caso, na página surge uma lista de todas as associações do Concelho, sem mencionar sequer quais as que pertencem ao agrupamento em questão e também sem qualquer contacto e, finalmente, num terceiro caso, na página não se encontra nenhum conteúdo e diz-se mesmo não existirem "artigos naquela categoria". Desta pluralidade de situações parece que se desenha um denominador comum, o papel muito residual que as páginas web desempenham no que se refere à divulgação das associações de pais e encarregados de educação. Repare-se que das dez páginas consultadas apenas cinco divulgam as associações e destas cinco apenas duas apresentam um conteúdo significativo no seu interior que pode ser potenciador da participação dos pais nas respetivas estruturas. Não obstante a responsabilidade dos agrupamentos nesta matéria, também não pode deixar de ser equacionado o papel das próprias associações, parecendo tratar-se mais de uma responsabilidade partilhada entre agrupamentos de escola e associações de pais e encarregados de educação.

\section{Considerações Finais}

No âmbito dos novos canais de comunicação entre a escola e a família, elegemos como objeto de estudo a análise de páginas web enquanto canal de comunicação e potenciador ou não da participação dos pais. Assim, no contexto de um exercício exploratório analisamos páginas web de agrupamentos de escolas da rede pública na realidade portuguesa, resultando dados pertinentes, ainda que com carácter de provisórios.

De modo específico, desta análise, ressaltamos que, de uma lista da totalidade de agrupamentos existentes em Portugal, selecionamos dez e que neste conjunto de agrupamentos a adesão a esta nova ferramente é total. Por outras palavras, destes dez agrupamentos por nós analisados todos possuem página web do agrupamento.

No interior destas dez páginas tivemos a oportunidade de verificar que apenas num caso existe espaço para os pais manifestarem os seus pontos de vista quanto ao funcionamento do agrupamento. Face a esta situação, parece haver por parte dos agrupamentos alguma insensibilidade/resistência ao feedback dos pais.

Numa última dimensão de análise, a página web enquanto instrumento de divulgação de estruturas de participação coletiva e direta, designadamente das associações de pais e encarregados de educação, registamos que cinco fazem esta divulgação e, destas cinco, apenas duas apresentam conteúdo em certa medida potenciador da participação dos pais nestas estruturas.

Desta análise preliminar, não podemos considerar que as páginas web constituem, na maioria dos casos dos 
agrupamentos, um instrumento que possibilita e potencia a $v o z$ dos pais.

\section{Referências}

Beneyto-Seoane, M. \& Collet-Sabé, J. (2016). Las relaciones digitales entre familias y escuela: análisis y propuestas. @tic.revista d'innovació educativa. No 16, pp.1-9.

Epstein, J; Coates, L; Salinas, K.; Sanders, M \& Simon, B. (1997). School, family, and community partnerships: your handbook for action. California: Corwin Press.

Fernandez-Enguita, M \& Vázquez Cupeiro, S (2017). La larga y compleja marcha del clip al clic: escuela y professorado ante el nuevo entorno digital. Espanha: Telefonica Fundación/Ariel.

Garreta Bochaca, J. \& Macìa Bordala, M. (2017). La comunicación família-escuela. In J. Garreta Bochaca (coord.) Familia y escuelas: discursos y prácticas sobre la participación en la escuela (pp.71-98). Madrid: Biblioteca Universitaria.

Lima, L. (1992). A escola como organização e a participação na organização escolar. Braga: Instituto de Educação/Centro de Estudos em Educação e Psicologia.

Martins, F. (2009). Gerencialismo e quase-mercado educacional: a acção organizacional numa escola secundária em época de transição. Braga: Tese de Doutoramento.

Sousa, S. (2013). Families, schools and the image communication in the education market. International Journal About Parents in Education. No7(V.2), pp.177-188. 